\title{
Can the Characterizationt Mandibular Canal Walls Indicate Possible Changes Caused by Osteoporosis?
}

\author{
Camargo $\mathrm{AJ}^{1}$, Faria $\mathrm{VA}^{2}$, Santos $\mathrm{EMCMF}^{1}$ and Plauto CA Watanabe ${ }^{1 *}$ \\ ${ }^{1}$ Department of Stomatology, University of Sao Paulo, Brazil \\ ${ }^{2}$ Department of Oral and Dental Biology, University of Sao Paulo, Brazil
}

*Corresponding author: Plauto CA Watanabe, Department of Stomatology, University of São Paulo, Av Do Café S/N Zip Code: 14040-904, Ribeirão Preto, Brazil

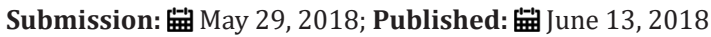

\section{Objectives and Introduction}

Osteoporosis is a worldwide epidemic, expresses high morbidity and mortality, resulting in high social [1]. Today, the examination of bone densitometry by Dual-energy X-ray absorptiometry (DXA) is the gold standard test for diagnosing the disease. However, its cost and viability are restricted mainly to underdeveloped and emerging countries. The availability of equipment for bone densitometry in Brazil in 2005 was 0.8 per 1 million inhabitants [2,3]. Panoramic radiography has been used to screen patients with low bone mineral density (BMD) evaluating the thickness and shape of the mandibular cortica [4-9]. The fact of panoramic radiograph cover important anatomical structures and have a low cost can be of great value to Dentistry providing the dentist the diagnosis of maxillary bone quality.

The aim of this opinion was consider to the results of a Camargo AJ et al. [10], thesis about the characterization of the mandibular canal walls to assess possible changes caused by osteopenia/ osteoporosis, indicating whether or not correlation between mandibular bone quality and systemic bone quality. Camargo AJ et al. [10]. Characterization the mandibular canal walls to evaluate possible changes caused by osteoporosis. Thesis de Master's degree defended in the Post-Graduate Program in Oral Diagnosis of FOUSP, 2013).

\section{Method}

The author used in her thesis the methodology employed by Alonso et al. [11] Used the Panoramic radiographs of 52 women, aged over 45 years $(56.4 \pm 8.4$ years) were analyzed and divided into three groups, according to results of the DXA (spine, femur and forearm): Group N (normal group, $n=26)$, group E $(n=18)$ with osteopenia and group $\mathrm{O}(\mathrm{n}=8)$ with osteoporosis. To characterize the pattern of cortical bone of the mandibular canal was used binary and skeletonized images from panoramic radiographs. The quantity of black pixels of each ROI was accounted.

\section{Results}

Significant differences were found between relative amount of black pixels in the region of the branch (R) of the mandibular canal $(\mathrm{p}<0.05)$ and the mean true when compared among groups of samples. In regions of the mandibular canal near the mental foramen (MF) and angle (A) statistical tests did not show the significant differences. Statistical analyses showed a significant difference in the average amount relative of black pixels in the region of the branch $(\mathrm{R})$ of the mandibular canal $(\mathrm{p}<0.05)$ compared among research groups, using the Tukey test.

\section{Discussion}

Until the moment no study has addressed the analysis of cortical mandibular canal as performed in this work despite of several researchers have studied the possibility of the use of panoramic radiography in dentistry as a way of screening patients with low bone mineral density [4-17]. The research was based on counting the number of black pixels obtained from the binarization of clippings radiographic images, which resulted in black pixels and white pixels of these binary images.

The Tukey test indicated that the mean of the group $\mathrm{N}$ and group 0 are significantly different. Thus, in the normal group of the cortical of the mandible canal were more radiopaque and evident (contained more black pixels) than the group with osteoporosis. Therefore the more radiopaque the cortical wall of the $\mathrm{CM}$, the structure is denser and healthier. This significant difference between the groups may be related to the low number of teeth present in women with osteoporosis as the mean found in group $\mathrm{N}$ was 18.730 and the group 0 of 3.075 , at consistent with several studies $[4-6,13,18,19]$. According to Alonso et al visual analysis of the morphological characteristics of the mandibular canal performed by an experienced radiologist had a high sensitivity value $(70.4 \%)$ when correlated to systemic bone diagnosed by DXA [11]. 
Xie et al. [20] noted that cortical thickness in the mandible angle decreases with aging and show significant differences between 76 and 86 years of age $(p<0.05)$. The authors found that the resorption in the wall of the CM was more prevalent in individuals with asthma (odds ratio 6.0), with thyroid disease (odds ratio: 3.04 ), and in individuals with a cortical thickness of the mandible in the region of angle of less than $1 \mathrm{~mm}$ thickness (odds ratio 2.74) By Camargo A] et al. [10], and I agree this increased resorption of higher cortical of the canal mandible may be related to dental loss and its proximity to the residual ridge, which stopped receiving stimuli of mastication. In the literature, the authors state that occur significant age-related changes in radiomorphometric indices obtained in different regions of the mandibular cortex (mental index, MI; antegonial index, AI and gonial index, GI) identifying low BMD and evaluating the role of osteoporosis in alterations of these indices, which can occur significantly in women and men [15,21,22].

\section{Conclusion}

These results suggest that the mandibular canal suffers action of osteoporosis and the analysis of cortical mandibular canal through the amount of black pixels can be a useful tool in the evaluation of patients with osteoporosis.

\section{References}

1. (1993) Consensus development conference: diagnosis, prophylaxis and treatment of osteoporosis. Am J Med 94(6): 646-650.

2. (2009) IBGE Scarcity and abundance: distribution supply diagnostic imaging equipment in Brazil.

3. (2002) Brazilian Consensus on Osteoporosis 2002. Rev Bras Reumatol 42(6): 343-354.

4. Klemetti E, Vainio P, Lassila V, Alhava E (1993) Cortical bone mineral density in the mandible and osteoporosis status in postmenopausal women. Scand J Dent Res 101(4): 219-223.

5. Taguchi A, Tanimoto K, Suei Y, Wada T (1995) Tooth loss and mandibular osteopenia. Oral Surg Oral Med Oral Pathol Oral Radiol Endod 79(1): 127-123.

6. Taguchi A, Tanimoto K, Suei Y, Otani K, Wada T (1995) Oral signs as indicators of possible osteoporosis in elderly women. Oral Surg Oral Meo Oral Pathol Oral Radiol Endod 80(5): 612-616.

7. Nakamoto T, Taguchi A, Ohtsuka M, Suei Y, Fujita M, et al. (2003) Dental panoramic radiograph as a tool to detect postmenopausal women with low bone mineral density: untrained general dental practitioners' diagnostic performance. Osteoporos Int 14(8): 659-664.

8. Arifin AZ, Asano A, Taguchi A, Nakamoto T, Ohtsuka M, et al. (2005) Computer-aided system for measuring the mandibular cortical width on panoramic radiographs in osteoporosis diagnosis. Proceedings of the SPIE Medical Imaging 57(47): 813-821.

9. Taguchi A, Ohtsuka M, Nakamoto T, Naito K, Tsuda M, et al. (2007) Identification of post-menopausal women at risk of osteoporosis by trained general dental practitioners using panoramic radiographs. Dentomaxillofac Radiol 36(3): 149-154.

10. Alonso MBCC, Cortes ARG, Camargo AJ, Arita ES, Haiter-Neto F, et al. (2011) Assessment of panoramic radiomorphometric indices of the mandible in a brazilian population. ISRN Rheumatol 2011: 854287.

11. Alonso MBCC, Oliveira-Santos C, Monteiro SAC, Watanabe PCA (2012) Morphological analysis of the mandibular canal in panoramic radiographs of the jaws as an indicator of bone mineral density. Osteoporos Int 23(4): 485-486.

12. Bozic M, Hren NI (2005) Osteoporosis and mandibles. Dentomaxillofacial Radiol 35(3): 178-184.

13. Arifin AZ, Asano A, Taguchi A, Nakamoto T, Ohtsuka M, et al. (2006) Computer-aided system for measuring the mandibular cortical width on dental panoramic radiographs in identifying postmenopausal women with low bone mineral density. Osteoporos Int 17(25): 753-759.

14. White SC, Rudolph DJ (1999) Alterations of the trabecular pattern of the jaws in patients with osteoporosis. Oral Surg Oral Med Oral Pathol Oral Radiol Endod 88(5): 628-635.

15. Taguchi A, Suei Y, Ohtsuka M, Otani K, Tanimoto K, et al. (1999) Relationship between bone mineral density and tooth loss in elderly Japanese women. Dentomaxillofac Radiol 28(4): 219-223.

16. Bollen AM, Taguchi A, Hujoel PP, Hollender LG (2004) Number of teeth and residual alveolar ridge height in subjects with a history of selfreported osteoporotic fractures. Osteoporos Int 15(12): 970-74.

17. Devlin H, Horner K (2002) Mandibular radiomorphometric indices in the diagnosis of reduced skeletal bone mineral density. Osteoporos Int 13(5): 373-378.

18. Devlin H, Karayianni K, Mitsea A, Jacobs R, Lindh C, et al. (2007) Diagnosing osteoporosis by using dental panoramic radiographs: The Osteodent project. Oral Surg Oral Med Oral Pathol Oral Radiol Endod 104(6): 821-828.

19. Alman AC, Johnson LR, Calverley DC, Grunwald GK, Lezotte DC, et al (2012) Diagnostic capabilities of fractal dimension and mandibular cortical width to identify men and women with decreased bone mineral density. Osteoporos Int 23(5): 1631-136.

20. Xie Q, Wolf J, Tilvis R, Ainamo A (1997) Resorption of mandibular canal wall in the edentulous aged population. J Prosthet Dent 77(6): 596-600.

21. Bras J, Ooij van CP, Abraham-Inpun L, Kusen GJ, Wilmink JM (1982) Radiographic interpretation of the mandibular angular cortex: A diagnostic tool in metabolic bone loss. Part I Normal state Oral Surg 53(5): 541-545.

22. Ardakani FE, Niafar N (2004) Evaluation of changes in the mandibular angular cortexusing panoramic images. J Contemp Dent Pract 5(3): 1-15.
Creative Commons Attribution 4.0

International License

For possible submissions Click Here

\section{Submit Article}

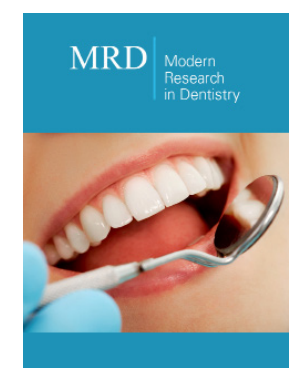

\section{Modern Research in Dentistry}

\section{Benefits of Publishing with us}

- High-level peer review and editorial services

- Freely accessible online immediately upon publication

- Authors retain the copyright to their work

- Licensing it under a Creative Commons license

- Visibility through different online platforms 